PHOTOCHEMISTRY AND ENZYMOLOGY OF PHOTOSYNTHESIS

Three Year Technical Progress Report

Bessel Kok, George M. Cheniae and Charles F. Fowler

MARTIN MARIETTA CORPORATION

Martin Marietta Laboratories

1450 South Rolling Road

Baltimore, Maryland 21227

Period: May 1, 1972 through April 30, 1975

\title{
MASTER
}

\section{Prepared for the UNITED STATES}

ENERGY RESEAR.CH AND DEVELOPMENT ADMINISTRATION

Under Contract E(11-1)-3326

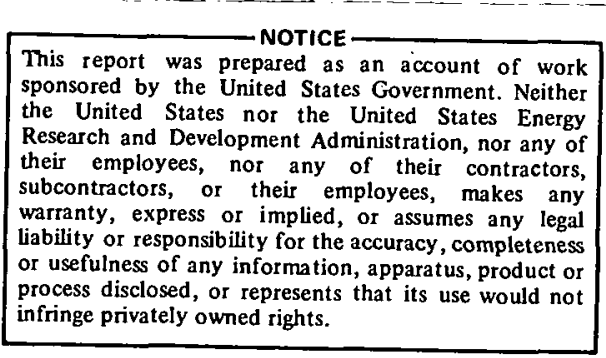




\section{DISCLAIMER}

This report was prepared as an account of work sponsored by an agency of the United States Government. Neither the United States Government nor any agency Thereof, nor any of their employees, makes any warranty, express or implied, or assumes any legal liability or responsibility for the accuracy, completeness, or usefulness of any information, apparatus, product, or process disclosed, or represents that its use would not infringe privately owned rights. Reference herein to any specific commercial product, process, or service by trade name, trademark, manufacturer, or otherwise does not necessarily constitute or imply its endorsement, recommendation, or favoring by the United States Government or any agency thereof. The views and opinions of authors expressed herein do not necessarily state or reflect those of the United States Government or any agency thereof. 


\section{DISCLAIMER}

Portions of this document may be illegible in electronic image products. Images are produced from the best available original document. 
"This report was prepared as an account of Government-sponsored work. Neither the United States, nor the Energy Research and Development Administration nor any person acting on behalf of the Commission.

A. Makes any warranty or representation, expressed or implied, with respect to the accuracy, completeness, or usefulness of the information contained in this report, or that the use of any information, apparatus, method, or process disclosed in this report may not infringe privately owned rights; or

B. Assumes any liabilities with respect to the use of, or for damages resulting from the use of, any information, apparatus, method, or process disclosed in this report.

As used in the above, 'person acting on behalf of the Commission' includes any employee or contractor of the Administration or employee of such contractor, to the extent that such employee or contractor of the Administration employee of such contractor prepares, disseminates, or provides access to, any information pursuant to his employment or contract with the Administration or his employment with such contractor."

During the reporting period we studied a number of aspects of Photosystem II and the reaction chain between the two photosystems. Several of these investigations have been reported in the papers listed on pages 27 and 28. The listing also includes a few review articles and notes on "biological energy conversion," a topic which we have given some thought in the past few years. To avoid redundancy, this report is restricted to studies in three areas which so far have not, or only partially, been published. The last of these three studies is described in the attached manuscript. 
Security Clause

I. Photoactivation of $\mathrm{O}_{2}$ Evolution and the Effect of 1 Functional $\mathrm{O}_{2}$ Evolving Centers on Trap Turnover of DCMU Poisoned System II

II. Kinetics of Light Induced Destruction of $\mathrm{O}_{2}$ Evolving

Centers by Tris and Subsequent Reactivation of $\mathrm{O}_{2}$ Evolution by Deactivators of S States

III. Oxygen Evolution 16

Techniques 16

Is the high value of $\mathrm{Y}_{3}$ due to an extra excitation? 17

Effects of reductants, states $S_{-1}, S_{-2} \quad 18$

High apparent $S_{0} / S_{1}$ ratios, a one equivalent 20 deactivator

Effect of oxidants, molecular oxygen $\quad 22$

Deactivation 23

Publications During Reporting Period $\quad \cdot 27$

References $\quad \cdot 29$ 
I. Photoactivation of $\mathrm{O}_{2}$ Evolution and the Effect of Functional $\mathrm{O}_{2}$ Evolving Centers on Trap Turnover of DCMU Poisoned System II.

During this reporting period, reprints describing the photoactivation of oxygen-evolving centers in $\mathrm{NH}_{2} \mathrm{OH}$-extracted algae ${ }^{(1)}$ and in dark-grown Chlorella ${ }^{(2)}$ were forwarded to your offices. These publications were logical extensions of our previous work on the site of inhibition of $\mathrm{O}_{2}$ evolution by $\mathrm{NH}_{2} \mathrm{OH}$ and on photoactivation of $\mathrm{Mn}$-deficient algae. $(3,4)$ This work showed that the same basic mechanism occurred for formation of active $\mathrm{O}_{2}$ evolving sites -- namely, a multiquantum process which resulted in incorporation of $\mathrm{Mn}^{+2}$ into the $\mathrm{O}_{2}$ evolving catalyst.

In contrast to certain green algae like Chlorella which are capable of synthesis of trapping centers in darkness, the development of the photosynthetic apparatus (pigment and thylakoid synthesis in higher plants is controlled via photomorphogenesis. Based on the results on the photoactivation of $\mathrm{O}_{2}$-evolving centers of dark-grown Chlorella, we suggested that in the development of the photosynthetic apparatus of higher plants, the formation of $\mathrm{O}_{2}$-yielding sites must be preceded by formation of the System II quantum-trapping centers. This supposition has proved. correct based on the work of others and founded on the following lines of evidence: 1) widely spaced $\left(t_{d}=15 \mathrm{~min}\right.$ ) flashes induce pigmentation and development of the trapping centers and their interconnecting chains in. etiolated leaves but do not induce the formation of $\mathrm{O}_{2}$ yielding centers ${ }^{(5)}$; 2) brief continuous illumination $(6,7)$ or paired flashes $\left(t_{d}=2-4 \mathrm{sec}\right)$ is 
required to activate the $\mathrm{O}_{2}$ yielding sites of such leaves ${ }^{(5-9)}$; the yield of active sites as a function of dark-time between flashes proved very similar to that observed by us with algae; ${ }^{(1-4)}$ and 3 ) the photoactivation of $\mathrm{O}_{2}$ evolution in leaves $(10)$ is correlated, as in algae, $(2,3)$ with incorporation of the larger $\mathrm{Mn}$ pool into the $\mathrm{O}_{2}$ yielding site. (11) It therefore appears that this process is fundamental to all photosynthetic oxygen-evolving tissue.

In continuation of our studies on photoactivation, we have made at least three different type observations which have made us question whether photoactivation is specific for only the insertion of $\mathrm{Mn}^{+2}$ into the $\mathrm{O}_{2}$ evolving center: 1) the flash induced oscillations of fluorescence attributed by Delosme $e^{(1,2)}$ and Zanke1 ${ }^{(13)}$ to differences in quenching efficiencies of various $S$ states ${ }^{(14)}$ of the $\mathrm{O}_{2}$ center are noticeably. absent in Mn depleted cells or chloroplasts, irrespective of manner of Mn depletion, but reappear with photoactivation (unpublished data); (2) the decay in darkness of the variable fluorescence from System II obtained in the presence of DCMU was markedly diminished in Mn depleted cells, irrespective of manner of $\mathrm{Mn}$ depletion, but returned to "normal" behavior following photoactivation; and 3) an increase of the smaller, more tightly bound System II $\mathrm{Mn}$ pool from 1 to $2 \mathrm{Mn} / 400 \mathrm{Chl}$ was observed with extended times of photoactivation.

Observation \#1 (above) appears to be generally consistent with current interpretations: 1) the fluorescence oscillations are attributable to differences of quenching efficiencies of the S states $(12-14)$ and 2) without manganese there are no $S$ states and no fluorescence oscillations but. with photoactivation the $\mathrm{S}$ states and fluorescence oscillations appear. 
Observation \#2 (above) did not appear to fit into currently accepted pictures for recombination of charges by dark reactions within the System II trap of DCMU poisoned tissue. Fig. 1 below represents an oversimplified scheme often appearing in the literature depicting separation of charges within a System II trap by absorption of a quantum and subsequent recombination of charges via unknown dark process leading back to the initial ground state level.

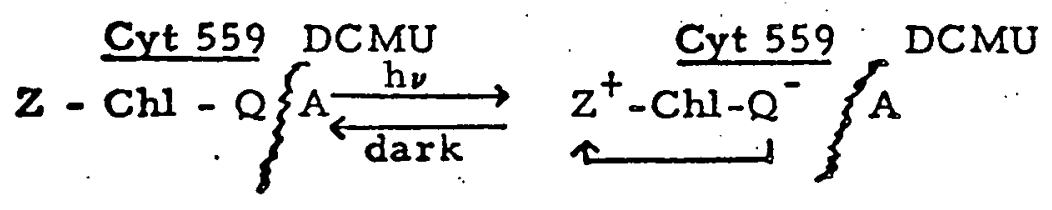

Fig. 1

The back-recombination of charges $\left(\mathrm{Z}^{+}\right.$with $\left.\mathrm{Q}^{-}\right)$has been reported to be inhibited by $\mathrm{NH}_{2} \mathrm{OH}^{(15)}, \operatorname{CCCP}(16,17)$, antimycin $\mathrm{A}^{(16,17)}$, tetramethylphenylenediamine (TMPD) ${ }^{(19)}$ and tetraphenylboron (TPB). (19) Bennoun (15) postulated that the inhibition of the back reaction by $\mathrm{NH}_{2} \mathrm{OH}$ was a consequence of the reduction of $\mathrm{Z}^{+}$by an electron from $\mathrm{NH}_{2} \mathrm{OH}$ thus leaving the high fluorescent state $\left(\mathrm{Z}-\mathrm{Chl} \mathrm{Q}^{-}\right)$. A similar explanation was offered by Homann for his observed effects obtained with TMPD and TPB. (19) On the other hand, Cramer attributed the inhibitory effects of $\mathrm{NH}_{2} \mathrm{OH}$, FCCP and Antimycin A to a conversion of high potential cyt 559 to low potential cyt 559, thus implying that cyt 559 (high potential) is a secondary quencher of fluorescence and participating in a cyclic path between $Q^{-}$and $\mathrm{Z}^{+}$. Implicit in Cramer's hypothesis is that the low potential cyt 559 cannot participate in this back reaction thus resulting in the locked-in state $\mathrm{Z}^{+}-\mathrm{Chl}-\mathrm{Q}^{-}$. 
We examined the rate of the back-reaction (fluorescence decay in the presence of $D C M U$ ) as a function of the concentration of $\mathrm{O}_{2}$ evolving centers. We depleted the concentration of $\mathrm{O}_{2}$ centers to different extents by growth of Chlorella in darkness, by extraction of autotrophic cells with $\mathrm{NH}_{2} \mathrm{OH}\left(10^{-5}\right.$ to $\left.2 \times 10^{-3} \mathrm{M}\right)$ and by autotrophic growth in a manganese depleted medium. In addition we then increased the concentration of $\mathrm{O}_{2}$ centers via photoactivation time-courses. We obtained the following results with whole cells of Chlorella and/or Scenedesmus:

1) Extraction of cells with increasing concentrations of $\mathrm{NH}_{2} \mathrm{OH}$ $\left(10^{-5} \mathrm{M}\right.$ to $\left.10^{-3} \mathrm{M}\right)$ followed by exhaustive washings to remove $\mathrm{NH}_{2} \mathrm{OH}$ resulted in increasing losses of $\mathrm{O}_{2}$ evolving centers. Both the initial rate and final extent of the fluorescence decay measured over the range of $50 \mathrm{msec}$ to $30 \mathrm{sec}$ (in the presence of $\mathrm{DCMU}$ ) were diminished by $\mathrm{NH}_{2} \mathrm{OH}$ extraction [(Fig. 1)]. The resulting rates of fluorescence decay and quantum yields of $\mathrm{O}_{2}$ evolution proved to be linearly correlated.

2) Results entirely similar to those above were obtained by culturing Scenedesmus cells autotrophically with increasing levels of Mn depletion.

3) Culturing of Chlorella in darkness with glucose as carbon source led to increasing loss of $\mathrm{O}_{2}$ evolving centers and increasing inhibition of the fluorescence decay. Again the rate of fluorescence decay and quantum yield of $\mathrm{O}_{2}$ evolution proved to be linearly correlated. Results of 1,2 and 3 indicate a close correlation between concentration of $\mathrm{O}_{2}$ evolving centers and the rate of fluorescence decay. The above treatments are known to deplete the $\mathrm{Mn}$ we associate with $\mathrm{O}_{2}$ evolving centers. 
4) We then inquired whether the increase in rate of fluorescence decay paralleled the increase in concentration of $\mathrm{O}_{2}$ centers induced by photoactivation. A single exponential time-course was obtained for both parameters [(Fig. 2)]. Moreover, compounds which inhibited the photoactivation of $\mathrm{O}_{2}$ centers yielded essentially equivalent inhibition the increase in rates of fluorescence decay induced by photoactivation (Fig. 3 ).

5) To further explore the relationship between active $\mathrm{O}_{2}$ evolving centers and rate of recombination of charges within DCMU poisoned System II traps, we studied the effect of $\mathrm{NH}_{3}$ and certain other amines on these two processes. It is known from the studies of Izawa et al ${ }^{(20)}$ that it is the uncharged species of certain amines which specifically inhibits $\mathrm{O}_{2}$ evolution. Thus the inhibition of $\mathrm{O}_{2}$ is highly $\mathrm{pH}$ dependent. Velthuys ${ }^{(21)}$ recently has given evidence from luminescence studies that $\mathrm{NH}_{3}$ effects $\mathrm{O}_{2}$ evolution by blocking the transition of $\mathrm{S}_{3}$ to $\mathrm{S}_{4}$ and $\mathrm{O}_{2}$ and slowing the transitions of $S_{1}$ to $S_{2}$ and $S_{2}$ to $S_{3}$. Under the conditions used by us the inhibition of $\mathrm{S}$ states by $\mathrm{NH}_{3}$ proved to be reversible, did not extract the $\mathrm{Mn}$ we associate with the $\mathrm{S}$ states, and did not increase rates of deactivation of the $S$ states.

Our studies of the effect of $\mathrm{NH}_{3}$ concentrations as a function of pH on $\mathrm{O}_{2}$ evolution and fluorescence decays again showed a close correlation under all conditions between inhibition of functional $S$ states and rate of fluorescence decays in the presence of DCMU.

6) Entirely similar results were obtained by decreasing functional S states of chloroplasts irreversibly by extractions with high concentrations of Tris $(21,22)$, or by directly inhibiting $\mathrm{O}_{2}$ evolution via the amine function of Tris. 
These results clearly reveal that the rate of fluorescence decay $\left(\mathrm{Q}^{-}\right.$oxidation) in DCMU poisoned cells or chloroplasts is a function of the presence of functional $\mathrm{O}_{2}$ centers and governed, at least in a part of the above studies by the $\mathrm{Mn}$ pool we associate with the $\mathrm{O}_{2}$ center.

The most general explanation we can offer currently can be depicted in a manner analogous to the interpretation given by Bennoun (15) and Lavorel ${ }^{(23)}$ for results obtained with hydroxylamine on fluorescence and luminescence decays:

$$
\text { I } \frac{h v}{\underset{k_{d} *}{\longrightarrow}} T^{-} \frac{e}{k_{d}^{* t}} T^{-}
$$

This model simply shows a photoseparation of charges $\left(T_{+}^{-}\right)$within the trapping center, a return to ground state via $k_{d}$ ", or to a "locked-in" fluorescence state $\left(\mathrm{T}^{-}\right)$via reduction $\left(\mathrm{k}_{\mathrm{d}}^{* *}\right)$ of the hole by some electron source. In our hands, in contrast to earlier reports in the literature, artificial electron donors like tetra-methyl-phenylenediamine, pphenylenediamine or hydroquinone do not significantly retard DCMU fluorescence decays in chloroplasts in which the $S$ states are not perturbed. Such electron donors are effective only after $\mathrm{S}$ state perturbations. Our results would imply that the earlier reports, a finite number of $\mathrm{O}_{2}$ evolving centers were inactive.

Acceptance of the above hypothesis necessitates postulating that all the means we have used to deplete $\mathrm{Mn}$ or to reversibly inhibit the $\mathrm{S}$ states (e.g. $\mathrm{NH}_{3}$ ) causes some subtle structural changes in the vicinity of the System II trap, thereby permitting reducing equivalents to 
equilibrate with the hole of the $\mathrm{T}_{+}^{-}$species. This simplistic explanation would be in accord with Vernon and Shaw's observations ${ }^{(24)}$ concerning the lack of photo-oxidation of diphenylcarbazide by $\mathrm{O}_{2}$ evolving chloroplasts but development of this photooxidative capacity as $\mathrm{O}_{2}$ centers specifically are inactivated. Still there are a number of other related observations by us which do not seem to fit into the above generalized, simplistic model, thus prohibiting publication.

We observed that hydrazine and related compounds yield the same effects as micromolar concentrations of $\mathrm{NH}_{2} \mathrm{OH}$ as reparted by Bennoun (15) and Bouges (25)-namely, a "locked-in" fluorescent state and a delay of the normal $\mathrm{O}_{2}$ oscillation by two flashes. Hydrazine, in contrast to $\mathrm{NH}_{2} \mathrm{OH}$, is without the troublesome destructive effects on the $\mathrm{O}_{2}$ center. Although we have not exhausted the chemical shelf, commonly used System II donors do not yield this effect.

Bouges $(25,26)$ explained her results on the basis of either ${ }^{(1)}$ binding of $2 \mathrm{NH}_{2} \mathrm{OH}$ by $\mathrm{S}_{1}$ without reduction of $\mathrm{S}_{1}$; or $(2)$ the reduction of $\mathrm{S}_{1}$ to $\mathrm{S}_{0}$ with binding of $1 \mathrm{NH}_{2} \mathrm{OH}$ to the $\mathrm{S}_{0}$ state. No data on reversal by flashes of the $\mathrm{NH}_{2} \mathrm{OH}$ effect on the fluorescence decay has appeared and, similarly, no data exist to discriminate completely between the above two hypotheses.

As an alternate explanation for our observed correlation between rate of decay of the fluorescence of DCMU poisoned System II and concentration of $\mathrm{O}_{2}$ centers, we might postulate that the recombination of charges depends on $S$ states and very possibly a specific $S$ state via a back-cycle within System II. In the context of cúrrent concepts, after finite darkness, System II retains one plus charge in the $S_{1}$ state. Assuming one conversion per flash in the presence of DCMU, normal treated chloroplasts would advance to yield $75 \%$ of the $S$ states in $S_{2}$. 
Presumably, reoxidation of $\mathrm{Q}^{-}$would occur via discharge of $\mathrm{S}_{2}$ back to $s_{1}$. Yet our preliminary experiments on the hydrazine effect is not removed by thorough washings even in the presence of $\mathrm{FeCN}$, a condition which, according to Bouges ${ }^{(26)}$, should oxidize the $S_{0}$. state back to $S_{1}$ with appearance of both the normal fluorescence decay and $\mathrm{O}_{2}$ oscillation. The problem of the possible influence of $S$ states on the rate of recombination of the charges in the trap will have to be resolved before a clear picture for all our data can be presented. Conceivably, such experiments may have direct bearing on the various $S$ states as well as the "misses" problem in $\mathrm{O}_{2}$ evolution. 
II. Kinetics of Light Induced Destruction of $\mathrm{O}_{2}$ Evolving Centers by Tris and Subsequent Reactivation of $\mathrm{O}_{2}$ Evolution by Deactivators

\section{of S States}

In recent years two reagents have been used rather extensively for the selective destruction of $\mathrm{O}_{2}$ evolution - - high concentrations $(0.8 \mathrm{M})$ of tris (hydroxy) aminomethane $(21,22)$ and low concentrations ( $1 \mathrm{mM}$ ) of hydroxylamine. (28) Neither of these reagents significantly affect either the System II or System I trapping centers or the interconnecting electron transport chain. $\mathrm{NH}_{2} \mathrm{OH}$ extraction ${ }^{(28)}$ does not destroy the ATP energy conservation sites, $(29,30)$; the effect of Tris extraction on ATP conservation rates is however rather contradictory: $(29,31-33)$

Though Tris extraction is frequently used, its mode of destructive action on $\mathrm{O}_{2}$ evolution is poorly understood as exemplified by wide variances of extraction times reported for inactivation of $\mathrm{O}_{2}$ evolution and the discrepancies reported for the effect of Tris extraction on the manganese pools of System II. $(11,34-36,38)$ According to Yamashita et al ${ }^{(34)}$ Tris extraction does not significantly diminish the chloroplast $\mathrm{Mn}$, a result in contradiction to earlier work by a number of workers $(11,34-36)$ including ourselves.

We have suspected that a part of the variability of the results in the literature on effects of Tris on chloroplast $\mathrm{Mn}$ might stem from: a slow diffusion rate through the thylakoid of the $\mathrm{Mn}$ released by Tris from the $\mathrm{O}_{2}$ evolving center on the inside of the thylakoid; coupled with unknown factors (see later) which catalyze the Tris induced release of $\mathrm{Mn}$ from the $\mathrm{O}_{2}$ evolving center. 
This supposition has been resolved partially by Blankenship and Sauer ${ }^{(37)}$ who showed by ESR that the Tris induced loss of $\mathrm{O}_{2}$ evolution was accompanied by appearance of the $\mathrm{Mn}^{+2}$ spin signal. This result confirmed and extended earlier work. ${ }^{(38)}$ Quantitation of the spins by Blankenship and Sauer showed that loss of $\mathrm{O}_{2}$ evolution was correlated with release of about two-thirds (4 Mn) of the total System II Mn pool ( $6 \mathrm{Mn} /$ System II trap), a result in agreement with our early data. (11) Under their conditions, however, this "free" $\mathrm{Mn}^{+2}$ remained on the inside of the thylakoid and diffused slowly across the thylakoid membrane. Loss of $\mathrm{Mn}^{+2}$ from the chloroplast was affected by washing but was highly dependent on the integrity of the thylakoid membrane. Such data have yielded some insight into the apparent discrepancies within the literature.

Still, there are a number of observations we have made which we feel will further clarify some of the literature and possibly will lead eventually to an understanding of the mechanism of release of Mn from the $\mathrm{O}_{2}$ centers by Tris and some other agents. Furthermore, as outlined later, these observations have given insight into the reactivation of $\mathrm{O}_{2}$ evolution in Tris extracted chloroplasts, a process first described by Yamashita and coworkers. (39) Our observations consist of the following:

1) Under any regime of light versus dark the kinetics of the loss of $\mathrm{O}_{2}$ yielding centers is first order with respect to time. In total darkness at $8^{\circ}$ and at $\mathrm{pH} 8.3$, the loss is slow (t $\left.1 / 2 \sim 25 \mathrm{~min}\right)$, it is accelerated by equilibration with ferricyanide, and is inhibited ( $t / 2$ $60 \mathrm{~min}$ ) by reduced indophenols and PMS but is unaffected by ferrocyanide. At lower $\mathrm{pH}$ values for $\mathrm{Tris}$ extraction $(\mathrm{pH} 7.6$ ), the decay in darkness 
becomes slower (t $1 / 250 \mathrm{~min}$ ), yet is still influenced by redox poising. The light induced rate is essentially unaffected by the lower pH value.

2) Light accelerates the decay of $\mathrm{O}_{2}$ evolution induced by Tris. This light effect is observed despite the fact that under the conditions for extraction $\mathrm{O}_{2}$ evolution per se is virtually totally inhibited.

3) This light driven process saturates at very low light intensities. We measured first order rate constants as a function of rate of absorbtion of $650 \mathrm{~nm}$ photons. With correction for the slow decay rate occurring in darkness, we calculate that only one hit/System II trap/200 sec is sufficient to yield half-maximal rate of decay. All our data thus far indicate that only 1 to 2 hits/System II trap is sufficient to induce $50 \%$ loss of $\mathrm{O}_{2}$ centers. Thus even with dense suspensions of chloroplasts, weak overhead room light is sufficient to cause significant effects. This light factor probably underlies some of the discrepancy concerning effectivity of Tris for destruction of $\mathrm{O}_{2}$ evolution. At these rates of quantum fluxes. photobleaching of chlorophyll b and carotenoid $(40)$ is not observed.

4) The rate of appearance of "free" $\mathrm{Mn}^{+2}$ spins as a consequence of Tris extraction is also increased by light. Thus far, however, we have no quantitative data relating loss of $\mathrm{O}_{2}$ and increase of $\mathrm{Mn}^{+2}$ spins as a function of quantum flux. We do know, however, that the compounds (see later) which "protect" against the light catalyzed loss of $\mathrm{O}_{2}$ evolution also diminish the rate of appearnce of $\mathrm{Mn}^{+2}$ spins.

5) Action spectra for the light effect indicate that the process is sensitized by System II. Adjustment of the rate of absorbtion of $700 \mathrm{~nm}$ light (System I) to yield a decay rate constant equivalent to that in weak $650 \mathrm{~nm}$ light (System II) showed that light absorbed by System II was 4-5 times more effective than System I. 
At these very weak rates of quantum absorbtions, the addition of DCMU afforded only partial protection against this light effect. This puzzled us since 1) the action spectrum for the light induced destruction of $\mathrm{O}_{2}$ centers by Tris indicated that System II quantum events were involved in the process and 2) in the absence of Tris, the System II traps are known to turnover in the presence of DCMU with a half-time of $\sim 0.8-1.0 \mathrm{sec}$. If our previously discussed data are valid (i.e. a high quantum yield process, half-saturated at $\sim 1$ hit $(150-200 \mathrm{sec})$, we might have suspected that DCMU would not have afforded any protection. This latter supposition however was based on the premise that the turnover of the System II traps in the presence of DCMU was unaffected by the high concentrations of Tris used in these experiments.

As discussed earlier Tris itself inhibits turnover of the DCMU poisoned traps. We measured rates of restoration of variable fluorescence of DCMU poisoned traps in Sucrose buffer and in Tris and obtained halftimes of $0.8 \mathrm{sec}$ and $60-70 \mathrm{sec}$, respectively. Moreover, in Tris the extent of restoration (opening of the traps) leveled off at about $35-40 \%$. These results suggest that even at weak rates of quantum absorbtions, turnover of the traps is significantly inhibited. This inhibition by Tris of trap turnover most probably explains the observed partial inhibition by DCMU of the light induced destruction of $\mathrm{O}_{2}$ centers by Tris. Addition of FCCP along with DCMU essentially abolishes the light induced decay of $\mathrm{O}_{2}$ centers. This effect of FCCP is not related to inhibition of trap turnover $(16,17)$, since FCCP yield no further inhibition of trap turnover over that obtained by Tris itself. At present, we tentatively ascribe this protective effect of FCCP in DCMU poisoned chloroplasts to its "activating properties" (see below). 
6) Agents (FCCP and ANT-2s) which accelerate decay of the S states $^{(41)}$ inhibit the light driven inactivation of the $\mathrm{O}_{2}$ centers. Reduced DCIP and PMS, which inhibit inactivation, also accelerate decay of the S states (observed in polarographic experiments). The concentration dependency of such agents for inhibiting Tris induced inactivation of $\mathrm{O}_{2}$ evolution is entirely similar to the concentration dependency for accelerating the deactivation of $\mathrm{S}$ states. The protective effect against Tris inactivation by such agents diminishes with increasing quantum fluxes in much the same way as they affect deactivation of the $S$ states.

The above observations pertain to the Tris induced inactivation of $\mathrm{O}_{2}$ evolution. Before giving any tentative interpretation to the above results, we briefly shall summarize our observations on the "reactivation of $\mathrm{O}_{2}$ evolution" in Tris extracted chloroplasts. (39) We do this because we believe the two processes are closely inter-related. Our reasons are as follows:

1) We studied the extent of "activation" as a function of concentration of inactive $\mathrm{O}_{2}$ evolving centers, predetermined by duration of extraction in light or in darkness. Chloroplasts inactivated via dark extraction could not be "activated" regardless of the concentration of inactive $\mathrm{O}_{2}$ centers $(0$ to 95\%). On the other hand, chloroplasts inactivated in weak light could be partially activated - the extent being variable amorig many different chloroplast preparations and never more (and usually less) than 50 percent. Blankenship and Sauer (private communication) on the other hand, have indicated, "complete activation" using reduced DCIP; they have (private communication, Blankenship) however confirmed our results showing that activation is possible only with chloroplasts inactivated in the light. Why this discrepancy in 
extent of activation remains a mystery to us. Summation of all of our many experiments in a plot of rates of $\mathrm{O}_{2}$ evolution of activated/nonactivated chloroplasts versus fraction of inactivated $\mathrm{O}_{2}$ evolving centers shows that the above ratio does not become greater than unity until at least 50 percent of the original active centers are inactivated via the light-driven process. With increasing concentration of inactive centers, this ratio increases almost exponentially. With dark inactivated chloroplasts, the above ratio remains at unity irrespective of the concentration of inactive $\mathrm{O}_{2}$ evolving centers.

2) The "activation" is obtained not only with reduced indophenols as shown originally by Yamashita ${ }^{(39)}$ but also by $2 \mu$ Molar concentrations of FCCP, CCCP and ANT-2s, $\mu$ Molar concentrations of PMS and other compounds all of which increase rates of deactivation of the S states.

The observed effects from CCCP, FCCP and ANT-2s (all are also uncouplers and affect proton movement) cannot be duplicated by other uncomplers such as gramicidin, methylamine, etc.

3) The light dependency for obtaining subsequent activation by deactivators(?) suggest that in the light some state is formed which can be subsequently discharged with a restoration of $\mathrm{O}_{2}$ evolution. We find the half-life of this presumed state to be about $60 \mathrm{~min}$. Thus far we have not been able to relate this presumed state with any known photosynthetic state. We do know that CCCP dramatically diminishes the rate of decay of ESR Signal II in untreated chloroplasts; diminishing the half-time from 60 min to a few seconds without appreciably altering the magnitude of Signal II formed in continuous light. $(42,43)$ Tris washing itself (light or dark? $)^{(42)}$ also accelerates decay of Signal II (t $\left.1 / 2=15 \mathrm{~min}\right)$ and, in 
contrast to FCCP, causes Signal II to decay completely within $60 \mathrm{~min}$. We have essentially confirmed such results.

At present, we cannot exclude the possibility that the long half-life simply reflects the loss of $\mathrm{Mn}^{+2}$ from within the thylakoid. This presumes that the activation of $\mathrm{O}_{2}$ evolution by deactivators(?) requires $\mathrm{Mn}^{+2}$. In this latter context we do.know (44, and confirmed here) that the spin signal from $\mathrm{Mn}^{+2}$, resulting from the extraction, disappears or is diminished upon activation. Even with this assumption, we are still without total explanations for:

1) The catalysis by light of Tris induced $\mathrm{Mn}$ release and loss of $\mathrm{O}_{2}$ evolution; 2) the dependence of activation on the prior light-induced destruction of $\mathrm{O}_{2}$ evolution; and 3) the curious dependence for activation on compounds which are known deactivators of the S states of $\mathrm{O}_{2}$ evolution. 


\section{Oxygen Evolution}

The hypothesis proposed 4-5 years ago by this laboratory to explain the peculiar behavior of photosynthetic oxygen evolution after a period of darkness has met general acceptance. A paper dealing with the rapid deactivation and other aspects of System II appeared in 1973. (45) Presentations dealing with other new aspects were given at the 1973 Gordon Conference,

and at the 3 rd International Congress on Photosynthesis in Israel, 1974.

The subject was discussed and reviewed in several other articles. $(47-49)$

Since for various reasons little of our more recent work has been published, we will briefly survey it in the following pages.

\section{Techniques}

The bare platinum electrode standardly used in this work, severely. influences, the system. Depending on its polarity, it.creates oxidizing or reducing conditions around the chloroplasts which are deposited on its surface. For instance, a negatively polarized electrode will reduce ferricyanide and show complex flash signals which reflect not only oxygen evolution but also ferricyanide reduction. "To avoid these complications, we developed Clark-type electrodes in which the platinum is covered with a thin membrane, permeable to gases but not to chemical additions to the suspensions. A fundamental drawback of covered electrodes, is their sluggish time response. With a very fragile membrane system, Forbush once was able to obtain $50 \mathrm{~ms}$ time response. Our routinely used membrane covered electrodes, however, respond to an $\mathrm{O}_{2}$ flash yield with a rise time of $0.2 \mathrm{sec}$ and a decay time $1 \mathrm{sec}$. We now have an array of techniques which afford easy handling of chloroplasts, rapid changing of 
liquids or gases, etc. These include the possibility of fixing chloroplasts on millipore filters. Albeit a bit tricky, these techniques have proven to be very convenient, affording experiments in a fraction of the time required in conventional manipulations. Since they seem to be more generally useful, we plan to publish these techniques in the near future.

Is the high value of $\mathrm{Y}_{3}$ due to an extra excitation?

From the outset, one of the main concerns about the hypothesis was the stability in the dark of the $\mathrm{S}_{1}$ state in addition to the ground state $\mathrm{S}_{0}$.

Based on fluorescence observations of Doschek and Kok ${ }^{(50)}$ and of Mauzerall ${ }^{(51)}$ and later also on observations of Fowler (52, unpublished) concerning flash induced electric field changes in chloroplast, we have considered the possibility that the first flash after a long dark period could induce two photoevents in System II instead of one. Babcock ${ }^{(53)}$ reported a high yield of phtooxidation of phenlylenediamine by the first flash of a sequence given to Tris washed chloroplasts. He considered, but did not stress the possibility of a double hit event. Such an event would offer an alternate explanation why the third and not the fourth flash in a sequence is maximal. Several years ago, Forbush and McGloin (unpublished) made observations to test this hypothesis. They measured flash yield sequences in which the intensity of the first or the second flash was varied but found no evidence for a "double hit" in the first flash. However, their experiment did not exclude the possibility of a double hit event smeared out over more than one flash (any material not "double hit" by the weak first flash, can still be double hit by the second, saturating flash). Later experiments, designed to test this possibility again did not reveal an 
extra photoact, although experimental precision was insufficient to draw a very firm conclusion.

Other evidence for or against an additional photoact in System II after a long dark period can be sought in the shape of the rise ("activation") curve of the oxygen rate in weak (modulated) light. If, instead of a trapping center with one plus charge, the $\mathrm{S}_{1}$ state were a System II unit capable of being double hit, the implication would be that in dark all traps return to the $S_{0}$ state. Since in weak light, no double hits occur, the "activation curve" should reflect a four-quantum process. If, on the other had, the majority of the traps revert to a "true"' $S_{1}$ state, the rise curve should reflect a three-quantum process. (Actually, in this approach, a more sensitive test is a comparison of the induction with or without two preflashes). Again, because of experimental variation, it proved surprisingly difficult to draw a definite conclusion, the weight of the evidence, however, favored the original hypothesis of a stable $S_{1}$ state in the darkness. We also have considered the more remote hypotheses, that in some peculiar way, System I could contribute to the formation of "S 1 ". We have measured flash yields of System I (viologen reduction) after long dark periods as a function of intensity, searching for a quadratic relation. None was found. Neither did flashes of different color, given to the blue-green alga, Anacystis, reveal interactions between Systems I and II. In sum, our search for a double hit process in photosynthetic $O_{2}$ production has been unsuccessful.

Effects of reductants, states $\mathrm{S}_{-1}, \mathrm{~S}_{-2}$

With the above techniques, we have studied the effect of various chemical reagents upon the ratio $S_{0} / S_{1}$ and other parameters of the system. 
Bouges ${ }^{(25)}$ first reported that in the presence of low concentrations of hydroxylamine, the oscillation of the oxygen yield is delayed by two flash numbers. Yields 3 and 4, normally high, are small and instead yields 5 and 6 are maximum. We found that this type of behavior can be induced with many reducing substances. Like hydroxylamine, hydrazine enters the system readily and acts in low concentration. It is less prone to cause permanent damage than hydroxylamine. However, there seems to be no "mystique" about the delay by two (instead of one) flash number other than a preference of the "O $\mathrm{O}_{2}$ box" to accept and retain reducing equivalents from these agents in pairs. Higher concentrations or longer incubation times lead to additional delay in the flash yield sequence $\left(\mathrm{Y}_{5}\right.$ declines and $\mathrm{Y}_{6}$ and $\mathrm{Y}_{7}$ become maximal). In addition, however, there is a decrease of $\mathrm{Y}_{\mathrm{ss}}$. We have observed that other reducing substances such as viologen, methylene blue or pyocyanin (partially reduced by hydrosulfite) can induce very similar phenomena. In this case, it is impossible to measure oxygen flash yields in the presence of the reduced reagents: because $Q$ is reduced, System II is not operative. With these low potential reductants, we used an alternation of incubation fluids, i. e.: 15-30 min in reduced methylviologen was followed by a 5 min exposure to ferricyanide. This oxidizing medium brought $Q$ and the other members of the electron transport system in the oxidized state. Presumably, however, it did not change the "delayed" flash yield pattern induced by the preceding reducing conditions. The latter conclusion rests on experiments with hydroxylamine or hydrazine. The effects by these compounds proved to be about the same with or without the simultaneous presence of a medium potential quinone, capable of keeping $Q$ oxidized, and did not materially revert during subsequent exposures to ferricyanide ( \pm benzoquinone) lasting as long as an hour. As 
was already noticed by Bouges ${ }^{(25)}$ a single flash given after hydroxylamine treatment allowed the system to fully restore in the dark albeit still very slowly (in our expts with a halftime of $\geqslant 20 \mathrm{~min}$ ).

These data seem to imply that reducing equivalents can be brought into the "O $\mathrm{O}_{2}$ box" in darkness but can only be removed from it by photochemical oxidation. This has tempted us to use the designations $S_{-1}, S_{-2}$ etc. for these states of the trapping centers.

Another mysterious phenomenon, which so far we have not pursued further, is the following: After a long exposure to reducing conditions (with viologen or pyocyanin present) followed by several minutes in ferricyanide in darkness, the first sequence of $(\geqslant 20)$ flashes can show very poor yields, but after another $5^{\prime}$ dark period, the system is again operative. High apparent $S_{0} / S_{1}$ ratios, a one equivalent deactivator

Not all reductants seemed to delay the maximum in a flash sequence after dark by two numbers $\left(\mathrm{Y}_{5}\right.$ high instead of $\left.\mathrm{Y}_{3}\right)$. Under many conditions one can observe $\mathrm{Y}_{4}>\mathrm{Y}_{3}$. We actually have spent (too) much effort in a search for conditions which would bring the system completely in the ground state $S_{0}$ (as should be reflected in $Y_{3}=0, Y_{4} \leqslant 4 x Y_{s s}$ ).

At one time we thought we had found reliable recipes to do this: (e. g. a 5-minute exposure to quite high concentrations of ascorbate). Such treatments produced flash yield patterns as shown in Fig. 2. This pattern was unaffected by subsequent incubation under oxidizing conditions (e.g. 20 hours in ferricyanide). However, we soon proved our original conclusion to be wrong: One or three preflashes given before the ascorbate treatment affected the subsequent yield pattern - as if these flashes were 


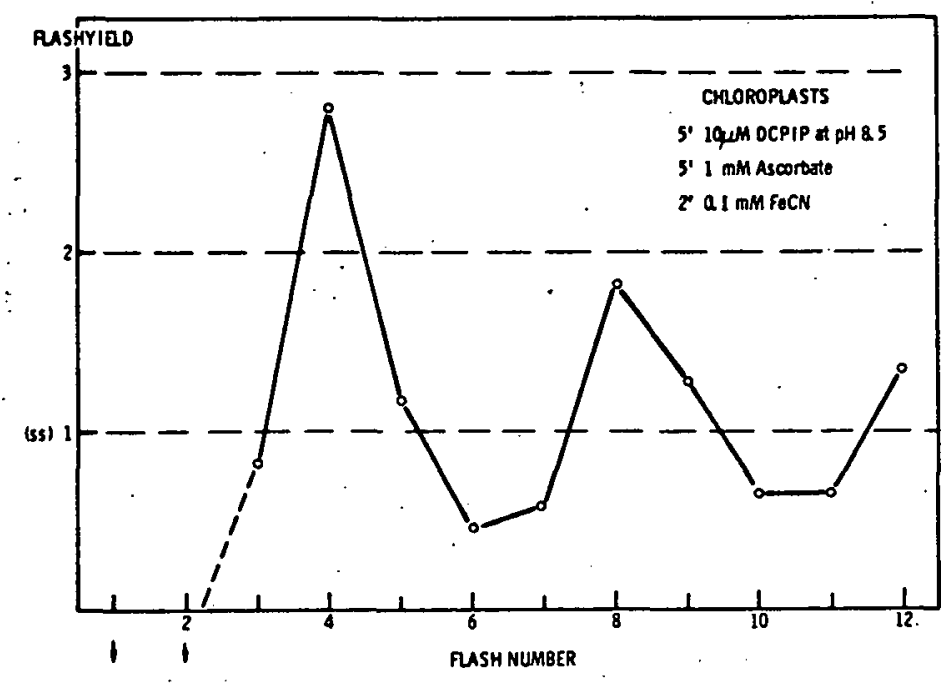

Fig. 2.

remembered by the system, i. e., the $S_{0} / S_{1}$ ratio was unaffected. It turned out that observation of this pattern depended on the flash spacing, $\mathrm{Y}_{4} / \mathrm{Y}_{3}$ being high with slow flash rates and nearly normal with a brief spacing. Evidently under these conditions one reducing equivalent enters the "O $\mathrm{O}_{2}$ box" which can reduce $\mathrm{S}_{2}$ and/or $\mathrm{S}_{3}$.

This discovery in turn helped explain another observation we had made much earlier: When repeating Bouges ${ }^{(26)}$ observation of the formation of $S_{1}$ in the presence of ferricyanide (reflected as a decrease of the $Y_{4} / Y_{3}$ ratio) we found that this effect was only temporary. Even under the most oxidizing conditions compatible with survival, and regardless of pretreatment, chloroplasts will, after a few hours, show a slow increase of the $Y_{4} / Y_{3}\left(S_{0} / S_{1}\right)$ ration (we have often used overnight or at times over the weekend incubations in presence of ferricyanide, benzoquinone or iridate). Originally, we made these experiments with the membrane covered electrode, which does not allow a rapid flash rate. Later, after we became aware of its existence, it proved that also in this case, the observed high ratio $S_{0} / S_{1}$ was due to the rapid one equivalent deactivator: 
$\mathrm{Y}_{3}$ remained high as long as the darktime between flashes was short. The nature of this "one equivalent deactivator" and its mode of operation and insensitivity to oxidizing conditions remains unresolved. However, it offers an alternate - - and preferable - explanation for the high $S_{0} / S_{1}$ ratio found by Bouges after treatment with reduced DPIP. Secondly, there seems to be a clear cut correlation with the behavior of one of the components of E.P.R. signal -- designated $\mathrm{II}_{\mathrm{S}}$ by Babcock and Sauer. ${ }^{(54)}$

\section{Effect of oxidants, molecular oxygen}

Joliot et al ${ }^{(14)}$ noticed that the ratio $S_{0} / S_{1}$ (reflected in the ratio $\mathrm{Y}_{4} / \mathrm{Y}_{3}$ ) can slowly change in the dark and tends to approach $1 / 3$. Bouges $(26)$ found this ratio to become very low in the presence of mild oxidants such as ferricyanide and as high as 1 in the presence of reduced DPIP. From these oberservations, she drew the conclusion that the reaction $\mathrm{S}_{1}+\mathrm{e}^{-} \rightleftarrows \mathrm{S}_{0}$ has a quite low midpoint potential: $\sim 300 \mathrm{mV}$. Since on the average, the 4 oxidation steps leading to $\mathrm{O}_{2}$ evolution must occur at a potential level of $820 \mathrm{mV}$, such a low midpoint potential of the $S_{0} / S_{1}$ system seemed highly unlikely to us. If the midpoint potential of the primary reductant of System II is around 0 volt it would imply that one of the four photoacts leading to oxygen would conserve only a small fraction of the energy available in the photon. Consequently, the other three steps would have to make up for a loss of more than $500 \mathrm{mV}$.

Our reluctance to accept Bouges' explanation was strengthened by another observation: $Y_{2}$ (the concentrations of $S_{2}$ precursors) tends to be higher in the presence of ferricyanide than in its absence. It would seem absurd to conclude from this observation that also the 
reaction $\mathrm{S}_{2}+\mathrm{e} \rightleftharpoons \mathrm{S}_{1}$ has a midpoint potential close to that of the ferriferrocyanide couple. To explain these data, we have recently $(46,49)$. forwarded the hypothesis shown in Fig. 3. It invokes an interplay of the

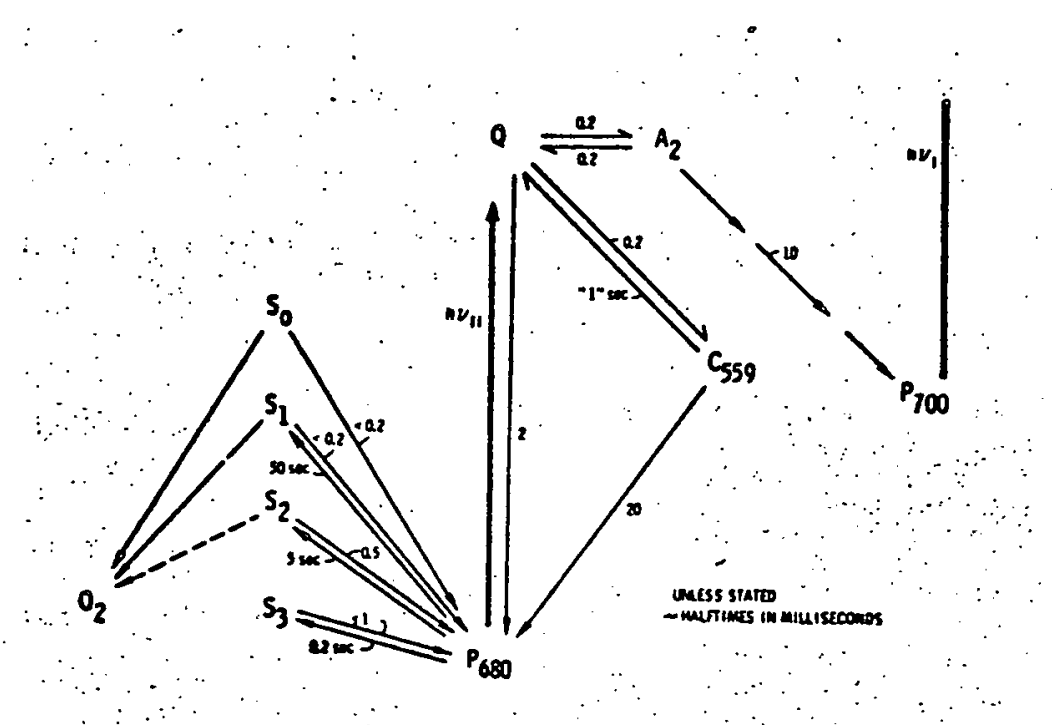

Fig. 3.

$S$ states, on the one hand with molecular oxygen, causing their oxidation, and on the other hand with a medium potential intermediate (cytochrome $\mathrm{b}_{559}$ ?) causing their reduction (deactivation). Although then, as now, we feel that this scheme is the only reasonable one available, we have as yet not obtained clear cut proof of an $\mathrm{O}_{2}$ effect. Adequate removal of $\mathrm{O}_{2}$ under oxidizing conditions in long term quantitative experiments with variable and unstable material proved technically difficult. So far the experiments seem to favor an $\mathrm{O}_{2}$ effect, however, a few seemingly impeccable observations, showed none.

\section{Deactivation}

Other experiments dealt with "deactivation", the loss of $S_{3}$ and 
$S_{2}$ in darkness. One of the most pronounced and unpleasant features of this process is its variability and unpredictability, especially in isolated chloroplasts. It is slowest and rather reproducible in whole algae in the presence of benzoquinone. For instance, in one of our most extreme observations, made with a fresh sample of Anacystis cells, the decay of $Y_{1}$ (loss of $S_{3}$ ) and concommitant rise of $Y_{3}\left(S_{1}\right)$ had a halftime of 7. 5 min. After an hour in the dark, $Y_{2}$ dropped only $30 \%$ and $Y_{4}$ remained constant. Such material also shows a long sustained oscillation of the flashyield, reflecting very few misses $(\geqslant 5 \%)$ which possibly reflects that System II operates close to optimally.

On the other side, deactivation can be as rapid as a fraction of a second for $\mathrm{S}_{3}$ loss and a few seconds for $\mathrm{S}_{2}$ : Usually, in these cases, the oscillation is poor and there seems to be a definite correlation between the $\%$ misses and the deactivation rate. So far a quantitative correlation has been beyond experimental reach and our present model accounts for this only qualitatively.

Due to the day to day variability of the system, our search for factors which affect deactivation has yielded rather qualitative results. The existence of two (reductive?) pathways has been long recognized and is accounted for in our model of Fig. 3.

It remains unclear, however, why, e.g. benzoquinone retards deactivation -- more or less independent of its state of reduction. As was first shown by Vater $^{(56)}$ dichlorophenol indophenol accelerates deactivation. We observed acceleration with the oxidized as well as the reduced form. Thus, as stated by Vater, there seem to be specific effects involved, apparently unrelated to redox state, midpoint potential or dissociation constant. These effects may correlate with the strong 
accelerating action of FCCP and similar agents described by Renger et al. $(57,58)$ The latter agents are known to affect membrane properties, uncouple phosphorylation and change the midpoint potential of cytochrome $b_{559}$ (presumably an endogenous electron donor to the oxidizing side of System II). Scheme Fig. 3, tacitly assumes that the low potential form of cyt. $b_{559}$ acts as a "rapid deactivator". This assumption, however, rests mainly upon extrapolation from the literature describing the behavior of this cytochrome.

Finally, since the loss of + charges is a reductive process, we have tried (along with attempts to change the $S_{0} / S_{1}$ ratio) to retard deactivation by adding oxidizing materials. Ferricyanide, and in a somewhat different fashion, benzoquinone, proved about as effective as any other oxidant. We have added just about any conceivable oxidant: iridate, Br water, various peroxides, permanganate, perchlorate, $100 \% \mathrm{O}_{2}$-enriched with ozone, etc. We found many new ways to kill chloroplast activity but so far no significant retardation of deactivation - only acceleration. Several of these reagents must have oxidized all intermediates which are known to operate in the photosynthetic chain and thus prevented electron donation from these sources to the $\mathrm{O}_{2}$ precursors.

Undoubtedly, the $\mathrm{O}_{2}$ system, as long as it is active is quite impermeable (Scheme, Fig. 2, assumes that the S states only communicate with $\mathrm{H}_{2} \mathrm{O}, \mathrm{O}_{2}$ and $\mathrm{P}_{680}$ ). Above, we have described that the system can spontaneously develop and/or retain 1, 2 or more "reducing equivalents" during prolonged incubation even under oxidizing conditions. This made us think of specific states of the $\mathrm{O}_{2}$ 
box denoted $S_{-1}, S_{-2}$, etc. The work of Cheniae et al has revealed that the $\mathrm{O}_{2}$ system (and presumably Mn catalysis) requires activation by light, each trapping center needing two or more photons to become operative. Possibly "in the limit" the reversal to a similar inactive state of the system occurs normally in the dark loss of $\mathrm{S}_{3^{\circ}}$. 
Publications During Reporting Period

"Efficiency of Photosynthesis," B. Kok, in: Horizons of Bioenergetics, Ed. A. San Pietro, Academic Press, N. Y., 153 (1972).

'Proton Trapping in Photosystem II of Photosynthesis, The Fluorescence Rise Curve in the Presence of DCMU, "W. W. Doschek and B. Kok, Biophys. J. 12, 832 (1972).

'Photoacts and Electron Transport," B. Kok, Symposium VI International Congress on Photobiology, Bochum, Germany (1972), in press.

'Rapid Light Induced Potentials in Spinach Chloroplasts, " C. F. Fowler and B. Kok, Abstract 417, VI International Congress on Photobiology, Bochum, Germany (1972).

"Effects of Hydroxylamine on Photosystem II. II. Photoreversal of the $\mathrm{NH}_{2} \mathrm{OH}$ Destruction of $\mathrm{O}_{2}$ Evolution, "G. Cheniae and I. F. Martin, Plant Physiol. 50, 87 (1972).

"O $\mathrm{O}_{2}$ Evolution in Photosynthesis," B. Kok, Oxidases and Related Redox Systems, Vol. 2, University Park Press 702 (1973).

"A Kinetic Analysis of the Oxidizing and Reducing Sides of the $\mathrm{O}_{2}$ Evolving System of Photosynthesis, "R. Radmer and B. Kok, Biochim. Biophys. Acta. 314, 28 (1973).

"Absence of Oxygen-Evolving Capacity in Dark-Grown Chlorella: The Photoactivation of Oxygen-Evolving Centers, "G. Cheniae and I. Martin, Photochem. Photobiol. 17, 441 (1973).

'Rapid Fluorescence Changes Observed in Chloroplasts: Their Relationship to the $\mathrm{O}_{2}$ Evolving System, "K. L. Zankel, Biochim. Biophys. Acta. 325, 138 (1973).

'Photosynthesis," B. Kok, p. 22 in: Proceedings of the Workshop on Bio-Solar Conversion, Report to NSF-RANN, Indiana Univ. (1973).

"Photosynthetic Regulation by Cations in Spinach Chloroplasts," T. Marsho and B. Kok, Biochim. Biophys. Acta. 333, 353 (1974).

"Kinetic Observation of the System II Electron Acceptor Pool Isolated by Mercuric Ion," R. Radmer and B. Kok, Biochim. Biophys. Acta. 357, 177 (1974).

IProton Evolution Associated with the Photooxidation of Water in Photosynthesis, "C. F. Fowler and B. Kok, Biochim. Biophys. Acta. 357, 299 (1974). 
"Direct Observation of a Light Induced Electric Field in Chloroplasts,"

C. F. Fowler and B. Kok, Biochim. Biophys: Acta. 357, 308 (1974).

"Evidence for a Cytochrome b in Green Bacteria," C. F. Fowler, Biochim. Biophys. Acta. 357, 331 (1974).

"Electron Transport in Photosystem II," B. Kok, R. Radmer and C.F. Fowler, p. 485 in: Proceedings of the Third International

Congress on Photosynthesis, Ed. M. Avron, Elsevier, Amsterdam (1974).

"Oxygen Evolution in Photosynthesis, ". P. Joliot and B. Kok, p. 387 in: Bioenergetics of Photosynthesis, Ed. Govindjee, Academic Press, New York (1975).

"Prospects of Photosynthetic Energy Production," B. Kok, Science and Technology 35, 519 (1975).

"Prospects of Photosynthetic Energy Production, " B. Kok, p. 133 in: The Current State of Knowledge of Photochemical Formation of Fue1, Boston University Report to NSF-RANN (1974).

"Photosynthesis: The Path of Energy," B. Kok, Plant Biochemistry, 3rd Edition, Eds. J. Bonner and J. Varner, Academic Press, New York, in press.

IPhotosynthesis, "B. Kok and R. Radmer, in: Chemical Mechanisms in Bioenergetics, Am. Chem. Soc. Monograph Series, D.R. Sanadi, Ed., in press.

"Energy Capture in Photosynthesis: Photosystem II," R. Radmer and B. Kok, Annual Reviews of Biochemistry, Vol. 44, in press. 


\section{REFERENCES \\ PROGRESS REPOR T}

1. Cheniae, G. M. and I. F. Martin, Plant Physiol. 50, 87 (1972).

2. Cheniae, G. M. and I. F. Martin, Photochem. Photobiol. 17, 441 (1973).

3. Cheniae, G. M. and Martin, I. F. Biochim. Biophys. Acta. 253, 167 (1971).

4. Radmer, R. and G. M. Cheniae, Biochim. Biophys. Acta. 253, $182(1971)$.

5. Michel, J. M. and C. Sironval, FEBS Lett. 27, 231 (1972).

6. Remy, R. Photochem. Photobiol. 18, 409 (1973).

7. Dujardin, E., Y. deKouchkovsky and C. Sironval, Photosynthetica $4,223(1970)$.

8. Inone, Y., Y. Ichikawa, Y, Y. Kobayashi, and K. Shibata, in Proc. 3rd Intl. Congr. on Photosyn. (Avron, M. , ed)(1975).

9. Inone, Y., Y. Kobayashi, E. Sakamoto and K. Shibata, Physiol. Plant. 32, 228 (1974).

10. Phung-Nhu-Hung, S., B. Houlier and A. Moyse, Physiol. Vegetale 279, 1669 (1974).

11. Cheniae, G. M. and I. F. Martin, Biochim. Biophys. Acta. 197, $219(1970)$.

12. Delosme, R., C. R. Acad. Sci. Paris 272, 2828 (1971).

13. Zankel, K., Biochim. Biophys. Acta. 325, 138 (1973).

14. Joliot, P., A. Joliot, B. Bouges and G. Barbieri, Photochem. Photobiol. 14, 287 (1971).

15. Bennoun, P., Biochim. Biophys. Acta. 216, 357 (1970). 


\section{REFERENCES}

PROGRESS REPOR T

(cont'd)

16. Homann, P., Biochim. Biophys. Acta. 245, 129 (1971).

17. Cramer, W. A., and H. Böhme, Biochim. Biophys. Acta. 256, 358 (1972).

18. Homann, P., Biochim. Biophys. Acta. 245, 129 (1971).

19. Homann, P., Biochim. Biophys. Acta. 256, 358 (1972).

20. Izawa, S., R. L. Heath, and G. Hind, Biochim. Biophys. Acta. 180, 388 (1969).

21. Vethuys, B. R., in Proc. 3rd Intl. Congr. on Photosyn.

(Avron, M. Ed) (1975).

21. (a) Nakamoto, T., D.W.Krogmann and B. Venneshland, J. Biol. Chem. 234, 2783 (1959).

22. Yamashita, T. and W. L. Butler, Plant Physiol. 43, 1978 (1968).

23. Ducruet, J. M. and J. Lavorel, Biochem. Biophys. Res. Comm. 58, 151 (1974).

24. Vernon, L.P. and E. R. Shaw, Biochem. Biophys. Res. Comm. 36,878 (1969).

25. Bouges, B., Biochim. Biophys. Acta. 234, 103 (1971).

26. Bouges, B., Biochim. Biophys. Acta. 292, 772 (1973).

27. Forbush, B., B. Kok and M. P. McGloin, Photochem. Photobiol. 14, 307 (1971).

28. Cheniae, G. M., and I. F. Martin, Plant. Physiol. 47, 568 (1971):

29. Ort, D.R. and S. Izawa, Plant Physiol. 52, 595 (1973).

30. Harth, E., and W. Oettmeir and A. Trebst, FEBS Lett. 43, 231 (1974). 
REFERENCES

PROGRESS REPOR T

(cont'd)

31. Yamashita, T. and W. L. Butler, Plant Physiol. 43, 1978 (1968).

32. Yamashita, T. and W. L. Butler, Plant Physiol 44, 435 (1969).

33. Ikehara, N. and E. G. Uribe, Arch. Biochem. and Biophys. 147, 717 (1971).

34. Yamashita, T., J. Truji, Y. Yamada and G. Tomita, Plant and Cell Physiol. 13, 353 (1972).

35. Selman, B.R., T. T. Bannister and R. A. Dilley, Biochem: Biophys. Acta. 292, 566 (1973).

36. Homann, P.H., Biochem. Biophys. Res. Comm. 33, 229 (1968).

37. Blankenship, B. and K. Sauer, Biochim. Biophys. Acta. 357, $252(1974)$.

38. Lozier, R., M. Baginsky and W. L. Butler, Photochem.

Photobiol. 14, 323 (1971).

39. Yamashita, T., J. Tsuji and G. Tomita, Plant and Cell Physiol. 12, 117 (1971).

40. Yamashita, T. and W. Butler, Plant Physiol 44, 1342 (1969).

41. Renger, G., Biochim. Biophys. Acta. 314, 390 (1973).

42. Lozier, R. H. and W. L. Butler, Photochem. Photobiol. 17, 133 (1973).

43. Babcock, G. T. and K. Sauer, Biochim. Biophys. Acta. 325, 504 (1973).

44. Blankenship, B., personal communication.

45. Radmer, R. and B. Kok, Biochim. Biophys. Acta. 314, 28 (1973).

46. Kok, B., R. Radmer and C. F. Fowler, in Proced. of 3rd Intern. Congr. on Photosynthesis, p. 485. 


\section{REFERENCES}

PROGRESS REPOR T

(cont' d)

47. B. Kok, in Horizons of Bioenergetics, (A. San Pietro, ed), Academic Press, N. Y. 153 (1972).

48. Joliot, P., and B. Kok, in Bioenergetics of Photosynthesis, (Govindjee, ed), Academic Press, N. Y. 387 (1975).

49. Radmer, R., and B. Kok, Ann. Rev. of Biochim., Vol 44, in press.

50. Doschek, W.W., and B. Kok, Biophys. J. 12, 832 (1972).

51. Mauzerall, D., Proc. Nat. Ac. Sci. 69, 1358 (1972).

52. Fowler, C.F., and B. Kok, Abstr. 417, VI Intern. Congr. on Photobiol., (1972).

53. Babcock, G. T., Ph. D. Thesis, Univ. Cal. Berkeley (1973).

54. Babcock, G. T. and K. Sauer, Biochim. Biophys. Acta. 376, 329 (1975).

55. Cramer, W. and W. Butler, Biochim. Biophys. Acta. 143, 332 (1967).

56. Vater, J., Bioch. Biophys. Acta. 292, 786 (1973).

57. Renger, G., Naturwiss. 56, 370 (1969).

58. Renger, G., B. Bouges and R. Delosme, Biochim. Biophys. Acta. 292, 796. (1973). 